\title{
Monitoring and Detection of Agricultural Disease using Wireless Sensor Network
}

\author{
Sarika Datir \\ K.J.College of Engineering and Management \\ Research ,Pune(University of Pune)
}

\author{
Sanjeev Wagh, Ph.D \\ K.J.College of Engineering and Management \\ Research ,Pune(University of Pune)
}

\begin{abstract}
Crop production quality and quantity can be enhanced using precision agriculture. One of the major products in India is grape. Major threats for grape farming are downy mildew and meal bug which spreads instantly and are hard to control. As the grape is very costly, Farmer needs to be very careful from the initial stage to harvesting to avoid infection of fungal disease and pest.

To prevent disease farmer has to apply fungicides and pesticides in huge quantity, it results in increased cost of production. Also another disadvantage is that grapes may carry toxins. To reduce cost of production and enhance the quality and quantity of the grapes, it is important to propose some mechanism that will help the farmer to detect the disease in early stage.

Existing systems for forecasting the disease mostly depends on image processing technologies. Drawback of the existing system is that they wait till symptoms appear and then only the disease can be detected. That's why such type of systems is unable to help treating the disease at an early stage. Grape diseases like downy mildew is mostly dependent upon weather based parameter like humidity, temperature and wind speed. When any favorable weather condition occurs zoospores in downy start generating spores that enters into the leaves of grape via stomata of the leaves. If favorable weather condition and the probability of disease is detected then it it very helpful for farmers to prevent infection of disease and reduce the cost of production.
\end{abstract}

\section{Keywords}

Wireless sensor network, GPRS, Downy Mildew, Disease, Pest, Vineyard, Pesticides, fungicides, Agriculture, grapes.

\section{INTRODUCTION}

In 2012 Around 36,888 tons grape was exported from India. Out of total export from the country, 99\% export was from Maharashtra while Andhra Pradesh exported 197 tons. Nasik contributes around $70 \%$ of Maharashtra's total grape export. Europa Gap is a farm management standard created in 1990s by European supermarket chains and their suppliers. The primary aim of the standard was to bring conformity to different retailers' supplier standards, which had been creating problems for farmers. It is now the world's most widely implemented farm certification scheme. Now a day European customers for agricultural products demand evidence of EurepGAP certification as a prerequisite for doing business. To increase export further farmer needs to be aware of standard required for export like UREPGAP. Many farmer those are doing grape farming are don't have that much literate hence they cannot understand and satisfy the rules and regulations of UREPGAP related to the application of pesticides and fungicides. Due to that their grapes rejected in residue analysis test and they cannot get more return on investment. Hence farmer needs special methods to apply inputs based only on requirements, instead of prevention.

Grapenet is web based software used to trace and track the grape export from India. By using grapenet system, EU registered around 18,007 plots from above mentioned states which cultivate export quality grapes. The major threats to grape farming are powdery mildew, Downy mildew and mealy bug. Powdery mildew can be identified by visualizing white powdery like spots on stems, leaves and the cluster. It spreads in dry as well as wet conditions. Downy mildew shows yellow to brownish spot on the leaves. Downy is very hazardous, once spread difficult to control it. It used for damages the grape yard in a short period of time.

The agrisense system developed in [6] detects downy mildew by collecting weather information and applying semi empirical model which provides the probability of downy mildew infection. Another system has implemented sensor [5] for detection of downy mildew based on image processing system. Italy and Spain also contributes for detection and analysis of downy mildew disease using weather information.

Methods used for controlling and preventing the pest and diseases in the vineyard include application of chemical like pesticides, fungicides and fertilizer. As there is no mechanism to identify the need of spraying chemicals, It's hard for farmers to decide whether to spray the chemical or not. As prevention is better than cure farmers apply spray chemicals in high quantity. Chemicals greatly contribute in polluting Soil hence result in wastage of natural resources. Now a day's many companies provide a weather service that helps to find the probability of disease but weather data provided by them is not located. Also it is important to detect any pests and diseases at its primitive stage in order to avoid overdose of chemicals on grapes.

\section{STUDY WNY MILDEW PEST}

Downy mildew is a fungal disease that appears in the vine yard rose garden and many other fruits and flower. Initial symptoms of disease appear green to brownish yellow spots on the upper side of leaves. Downy spores attached to the lower side of the leaves. When spores died on the lower side that the yellow spots gets appear on the upper side. The downy mildew disease developed in three stages. a) PrePenetration phase) Penetration phase c) Post- Penetration phase. As shown in Fig. 1 primary infection of downy mildew mildew starts from a fungus that overwinters as spores inside fallen leaves. When humidity increases oospores produces sporangium, sporangium produces zoospores, zoospores produces aspersorium that is called as an organ of attachment. In penetration phase aspersorium apply mechanical pressure on leaves and produces some enzymes and toxins and get entry into the internal part of the leaves. In post penetration 
phase after successful merging in leaves it produces historia. Historia is an organ of absorption of food form cells. Due to this respiration process reduce the metabolism rate relatively work of energy production of microchondrion is reduced.

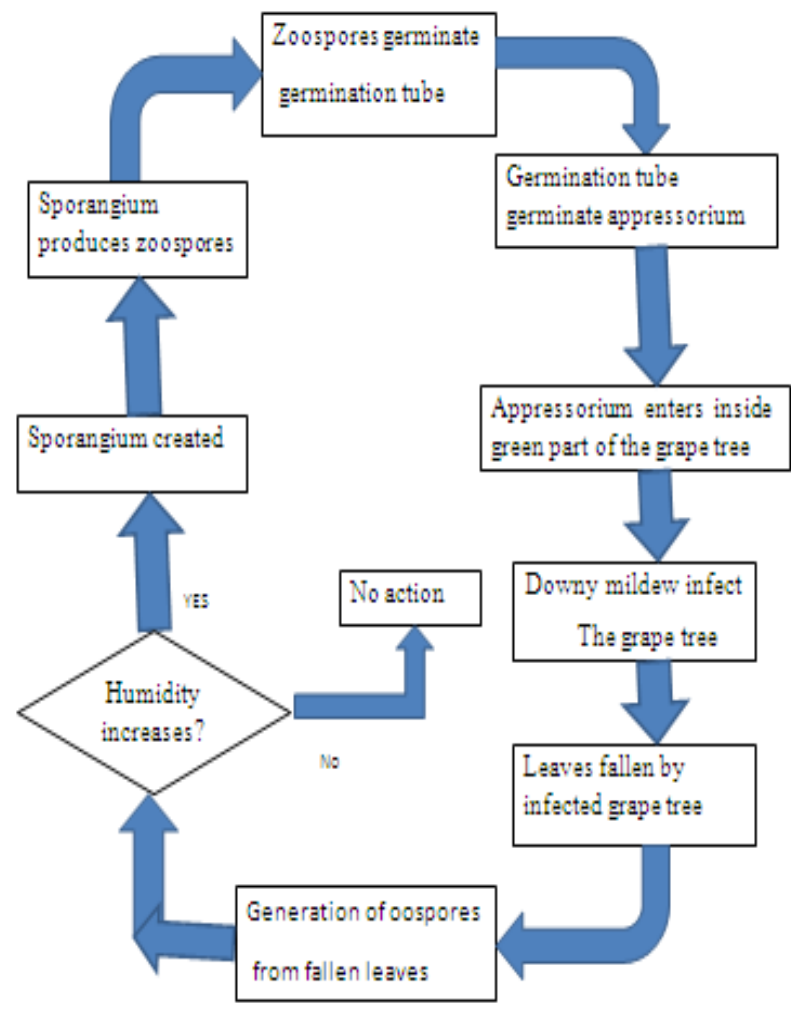

Fig 1 : Life cycle of Downy Mildew pest

\section{LITERATURE SURVEY}

"A GSM-based remote wireless automatic monitoring system for field information" [2]. It is an automated system that collects real time weather data and monitors environmental fluctuations. In Taiwan bacteria dorsalis is the major insect that reduces the quality of common vegetables and fruits. The system allows controlling bacteria dorsalis pest by using automated trapping tubes and reducing agricultural losses. This research finds the result for testing accuracy of GPS positioning system and counting of the fly trapping tubes. Actual field test and statistical analysis are performed for measuring counting accuracy of fly trapping tubes. With the help of this system it is possible to collect accurately large and long distance timely variable field data.

In research [1] Feasibility study on field data acquisition system is complete. Objective of study was to develop a short packet format for efficient transformation of environmental parameters to some central location. The system gives better results of Authentication of data, performance of developing the packet format and correctness of data. The system is implemented for monitoring the weather data for checking accuracy of developed packet format.

The sensor is developed for detection of downy mildew pest in various crops in agriculture [4]. Sensors contain modules for image grasping, image pretreatment and detection of downy mildew. Camera sensors are used in this system that is not cost effective if end user required installing a large number of nodes. In this system downy mildew is detected based on detection of visual symptoms of disease with the help of image processing.

The agrisense system developed [6] to detect downy mildew by collecting weather information and applying semi empirical model which provides the probability of Information of downy mildew.

Automatic weather data acquisition by using GPRS [7] with mobile phone control, that offers new remote monitoring and analysis system. Weather data are sent to remote server using GSM/GPRS terminal. Weather data available to end user it can handle it using LabView or mobile phone.

Location aware system (LAS) [8] that reduces number of spray by performing spay only when and where it required. LAS is pest management system to control Olive fruit fly and reduces cost of pesticide treatment.

"Downy Mildew of Grape" by Michael A. Ellis [9], Discuss on downy mildew disease. Downy mildew is very major disease in the US and Asia and Europium region. The fungus can cause direct yield losses by rotating from florescence, leaves, cluster and shoots. Downy mildew developed and spread within very short period and can damage whole plots, it is very important to detect it in a primitive stage. Traditional methods used by farmers to identify disease or pest are only with the help of observation and experience. Identify disease with the help of observation is not possible when area covered by crop is very large.

\section{MOTIVATION}

Grapes are one of the important products and are of major interest commercially politically and socially in the global market. In Global market demand of grape and grape product are very huge. Grape farming is the main source of earning of my family since childhood because of that I have experienced various problems faced by farmer due to drastic fluctuation in the environment, soil compositions, pest and insects. I always wonder to see the grape disease and their results. Due to this I get motivated to study the problem of farmers. Grape cultivation in India faces serious threat from several insect pests and diseases. The major fungal diseases and insect pests include downy mildew, powdery mildew, mealy bug and trips respectively which cause enormous economic loss to the grape sectors every year. . Downy mildew is a fungal disease that is spread within very less time period and once spread it is very difficult to recover from that infection. The grape product process requires a huge initial investment. From cutting to harvesting farmer needs to be very careful to avoid infection of fungal disease and pest. Small ignorance can lead to heavy loss

Traditional agriculture where tasks such as planting, harvesting, and application of agricultural inputs are based on predetermined schedule and experience of the farmer. Farmer don't have way to find out actual requirement of crops hence them apply excess amount of chemicals that carries toxic on grape and increases cost of production. In today's scenario increasing input cost and returning commodity prices precision agriculture is very necessary to reduce agricultural input and increase product cost.

Indian agricultural plots are scattered in different locations. In case of grape farming, it is very necessary to take precautionary measure if unfavourable weather condition detected for grape. When one farmer has acres of vineyard and it is situated at five different locations that are $10 \mathrm{~km}$ away from each other. Hence it is very difficult to visit all five locations at very early morning and based on weather 
condition on location take the decision of spraying different pesticides. There should be a system that make's large scale remote communication possible and remotely monitor the plots and gives disease probability and weather fluctuation plot wise hence farmer can apply precautionary measures at a primitive stage of disease.

As per actual field survey, $90 \%$ farmer applies chemical directly without identifying any symptoms of disease. Such rapidly applying chemicals on crop pollute soil as well as the environment. It also pollutes nearby water resources hence day by day sources of drinking water gets reduced. Indian farmer mostly follows the method of prevention instead of avoidance. More application of chemicals on crop causes some severe human diseases also. Health risks from natural chemicals in food grain are even greater than the risks from pesticide residues.

Most of the time it is not possible for a farmer to available on farm. If exactly at that time unfavourable weather condition is occurred for downy mildew or any other disease then it is not possible for farmers to protect vineyards from disease infection. Such problem only be solved by using remote monitoring and remote action taken technologies.

A disease like Downy mildew when infect one plot, they automatically infect nearby grape plots. The farmer has to very careful about infection of Downy mildew in nearby vineyards.

\section{PROPOSED WORK}

In proposing solution we concentrate on the detection of Downy mildew on early stage by using the location specific monitoring node. This is a real time system that detects downy mildew pest based on weather data. Novelty of Proposed system is to provide remote node with very low cost and the farmer has to maintain only remote node instead of maintaining server node at his farm. He can access the central server with the help of web application. To access web application he can use tabs, Notebook, Desktop PC or mobile phone with internet access. He gets all details of weather conditions and disease probability of his farm plot wise.

For remote node construction AVR board will be used. For construction of AVR board Express PCB software is to be used. Microcontroller programming is to be done using WinAVR software. WinAVR is open source software and it is specially implemented for the Atmel AVR series of microprocessor. WinAVR provides avr-gcc for compiling, avrdude for programming and avr-gdb for debugging. Bluetooth controller is to be used for connecting to android device. Here we can use Internet/GSM/GPRS facility of android device. Sensor data send to the central server by using android device. Originality of the proposed system is it will use GPRS, GPS and GSM feature of android device instead of integrating actual GSM, GPRS and GPS module on remote node. It will reduce size as well cost of the remote node.

The end user of the proposed system is farmer, he uses web application that is connected to a central server for real time updating of weather data. With the help of the web application farmer can monitor grape farm for disease probability as well as current weather condition. The farmer can give command from web application to start chemical spray device.

Fig. 2 shows the general layout of proposed system. Hardware part in remote nodes are sensors signal conditioning, analog to digital converter, Micro controller, Driver, Actuators, Bluetooth controller and android device for GSM and GPS , and GPRS functionality. Sensor data send to the android device using Bluetooth controller. The android device then sends that data to a central server using GSM or GPRS technology. The end user web application is implemented using Java technology. The database is provided to this web application by the central server. By using web application farmer can see weather data and downy mildew disease probability of specific plot. With the help of the web application farmer can remotely give command to start spraying of pesticides automatically if disease probability is severed. If disease probability is severe emergency message is sent to the farmer's registered mobile number.

Disease prediction algorithm used for the proposed system is a Naïve Bayes classifier. It is deterministic model used to find the Posterior probability of class. It assumes that the presence of any feature of class is independent on other feature of the class. Given the class variable. For example a fruit may be a considered an orange if it is yellow, round and 4 inch diameter. Even if all these feature depend on each other or existence of each other. Naïve Bayes classifier considers that all these independent features contribute to the probability that this fruit is an orange.

To prove the efficiency of and effectiveness of proposed system naïve Bayes classifier algorithm is used. It has three terms. Training data to this algorithm is actual weather data based on humidity and temperature parameter. Class label is assigned with this weather data i.e Disease is YES or NO Then by using Naïve Bayes classification. The proposed system predicts the class label of each table. Now consider that tuple $\mathrm{X}$ has to be classified to predict the disease probability YES or NO.

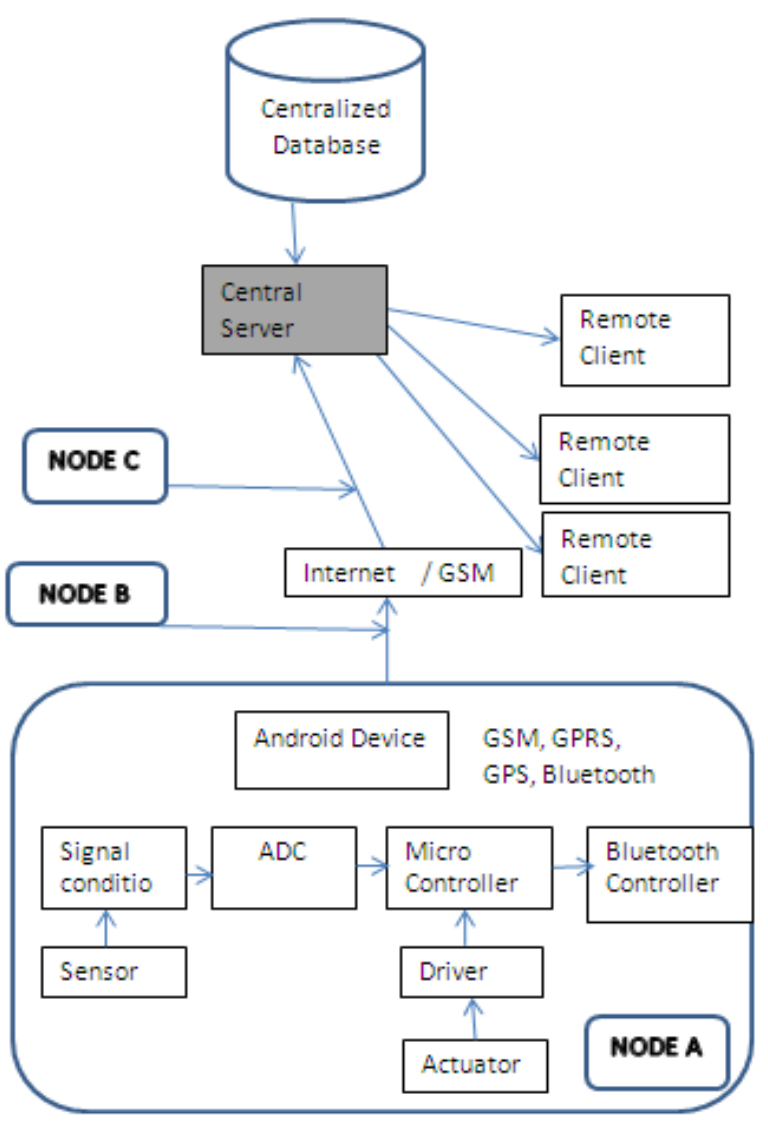

Fig. 2 : Layout of proposed system 
$X=($ Min. Temp=27,Max. Temp=45, min Humidity $=40$, Max. Humidity $=100$ )

Here the author has considered actual weather data set to predict a class label of tuple X. First calculate, prior probability of each class based on training tuples.

$\mathrm{P}($ Disease $=\mathrm{YES})=\mathrm{PPY}$

$\mathrm{P}($ disease $=\mathrm{No})=\mathrm{PPN}$

Now compute the conditional probability. $\mathrm{P}(\mathrm{X} \mid \mathrm{Ci})$, for $\mathrm{i}=1,2,3,4$

$\mathrm{P}($ Min. Temp $=27 \mid$ Disease $=$ YES $)=\mathrm{y} 1$

$(\mathrm{P}($ Min. $\mathrm{Temp}=27 \mid$ Disease $=\mathrm{NO})=\mathrm{n} 1$

$\mathrm{P}($ Max. Temp $=45 \mid$ Disease $=$ YES $)=y 2$

$\mathrm{P}($ Max. Temp $=45 \mid$ Disease $=\mathrm{NO})=\mathrm{n} 2$

$\mathrm{P}($ Min. Humidity $=40 \mid$ Disease $=\mathrm{YES})=\mathrm{y} 3$

$\mathrm{P}($ Min. Humidity $=40 \mid$ Disease $=\mathrm{NO})=\mathrm{n} 3$

$\mathrm{P}($ Max. Humidity $=100 \mid$ Disease $=$ YES $)=\mathrm{y} 4$

$\mathrm{P}($ Max. Humidity $=100 \mid$ Disease $=\mathrm{NO})=\mathrm{n} 4$

Using above probabilities we obtain

$\mathrm{P}(\mathrm{X} \mid$ Disease $=\mathrm{YES})=\mathrm{y} 1 * \mathrm{y} 2 * \mathrm{y} 3 * \mathrm{y} 4=\mathrm{PY}$

$\mathrm{P}\left(\mathrm{X} \mid\right.$ Disease $=\mathrm{NO}=\mathrm{n} 1 *_{\mathrm{n}} 2 *_{\mathrm{n}} 3 *_{\mathrm{n}} 4=\mathrm{PN}$

Now to find class Ci compute,

$\mathrm{P}(\mathrm{X} \mid$ Disease $=\mathrm{YES}) * \mathrm{P}($ Disease $=\mathrm{YES})=\mathrm{PPY} * \mathrm{PY}=\mathrm{Y}$

$\mathrm{P}(\mathrm{X} \mid$ Disease $=\mathrm{NO}) \mathrm{P}($ Disease $=\mathrm{NO})=\mathrm{PPN} * \mathrm{PN}=\mathrm{N}$

By actual mathematical calculation value of $\mathrm{Y}$ is 0.0049 and value of $\mathrm{N}$ is 0.0089 . Therefore naïve Bayes classifier predicts Disease $=\mathrm{NO}$ for giving tuple $\mathrm{X}$.

\section{DISCUSSION}

Short packet format [1] was developed for transformation of various remote node data to a central server. Here they used short message service feature of GSM technology instead of that one can use GPRS technology for frequent data transfer and real time monitoring of weather parameter.

A system implemented [2] uses GSM for remote communication. This work can be extended for detection of any type of pest by detecting favorable weather condition in the farm with the help of GSM and Wireless sensor network. One can also extend this system for any type of large scale, long distance communication for monitoring purpose.

Anshuka Srivastava [5] implements a sensor for detection of downy mildew pest. They take images of leaves of grape by using camera sensor. With the help of image processing if visual symptoms of Downy Mildew are detected then send an alert to the farmer. Visual symptoms of disease are appearing only after third stage of disease. Means disease is not detected here in the primary stages. Downy mildew infection is spread only when favorable weather condition occurs. If the thfavorable weather condition is detected, then disease is detected in primitive stage can be treated early.

Agriscence system implemented by IIT researchers [6] detects downy mildew by applying empirical model on weather data. They implemented this system for Sula vineyard in Nasik, Maharashtra but it is not useful for farmers.

\section{CONCLUSION}

Identify disease in its primitive stage and suggest pesticides, fungicide names and quantity are very emergence need of modern agriculture. In traditional agriculture disease is identified only by real time observation but now a day area covered by any type of fruit field increases hence it is not possible to identify diseases by real time observation only. Demand for importing grape from India especially from Maharashtra is increasing tremendously hence it's very essential to protect grape from disease and maintain quality to fulfil the criteria for exporting grape to other countries.

Now a day most of the people those doing service also take an interest in various types of fruit farming but they don't have knowledge of conventional agricultural methodology. They need special type of help and support system to become successful in agriculture. If these farmers will use proposed system, then it will give them a weather record of vineyard plot wise and probability of disease infection remotely. They can start spraying application remotely if disease probability is severed. By using proposed system they can detect and prevent the disease remotely from any location in the world.

\section{REFERENCES}

[1] Tseng, C.L., Jiang, J.A., Lee, R.G., Lu, F.M., Ouyang, C.S., Chen, Y.S., Chang, C.H., 2006. "Feasibility study on application of GSM-SMS technology to field data acquisition" Comput. Electron. Agric. 53, 45-59.

[2] Jiang,J.A., C. L. Tseng, F.M. Lu, E. C. Yang, Z. S. Wu, C. P. Chen, S. H. Lin, K. C. Lin and C. S. Liao. 2008. "A GSM-based remote wireless automatic monitoring system for field information: A case study for ecological monitoring of the oriental fruit fly, Bactrocera dorsalis (Hendel)." Computers and Electronics in Agriculture 62(2): 243-259.

[3] Jyh-Cherng SHIEH , Jiing-Yi WANG, Tzu-Shang LIN, Chi- Hung LIN, En-Cheng YANG, Yao-Jen TSAI, Hsien-Tsung TSAI, Ming-Tzu CHIOU, Fu-Ming LU, and Joe-Air JIANG "A GSM-based Field Monitoring System for Spodoptera litura (Fabricius) " EAEF 4(3) : 77-82, 2011.

[4] Liu, Y.C., 2002. "A review of studies and controls of the oriental fruit fly (Bactrocera dorsalis (Hendel)) and the melon y (B. cucurbitae Coquillett) in Taiwan (Diptera: Tephritidae). In: Wang, S.C., Ho, C.C., Chen, C.C., Chen, W.H. (Eds.), Proceedings of the Symposium on Insect Ecology and Fruit Fly Management, Special Issue, No. 4

[5] Anshuka Srivastava, ShugenMa, Kousuke Inoue. "Development of sensor for automatic detection of downew mildew disease" Proceeding of the 2004 International conference on Intelligent Mechatronics and automation Chengdu, china august, 2004.

[6] Ipsita Das, CPRG Naveen, Shailendra S. Yadav, bhishek, A. Kodilkar, N.G.Shah, S.N.Merchant, U.B.Desai, 2011."WSN Monitoring of Weather and Crop Parameters for Possible Disease Risk Evaluation for Grape Farms Sula Vineyards, A Case Study".

[7] Raul Ionel, Gabriel Vasiu, Septimiu Mischie, "GPRS based data acquisition and analysis system with mobile phone control. ELSEVIER - Measuremnt 45(2012) 
[8] Costas M. Pontikakos, Theodore A. Tsiligiridis, Constanttine P. Yialouris, Dimitris C. Kontodimas "Pest management control of Olive fruit fly based on a location -awre agro-environmental system.. ELSEVIER Computer and Electronics in agriculture 87(2012)

[9] Michael A. "Downy mildew of grape", Ellis, Department of plant pathology.

[10] Report on plant disease, downy mildew on disease, Department of crop science, University of Illinois at urban champaign,2004. 198.

\section{AUTHORS}

Sarika Datir persuing her Masters in Computer science from K. J. College of Engineering and Management Research, Pune. Her research interest include computer Network, Wireless Sensor Network, Agriculture problem solving.
Prof. Dr. Sanjeev wagh received his $\mathrm{PhD}$ in computer Scinece \& Engineering from the SRT Marathavada University, Nanded and Masters degree from University of Pune, India. Currently he is a postdoctoral researcher at Center for TeleInfrastructur(CTIF) at Aalborg University (AAU), Denmark. His research interest includes Computer Networks, Network Algorithmics, wireless sensor networks, etc. He is currently involved in the research work of intelligent wireless communication evaluation and energy optimization in wireless sensor networks.

Sanjeev Wagh is a member of IEEE, ACM, FIETE, FIE and LMISTE. He is active steering committee member for the various International Conferences, workshops and as a technical program committee member and reviever for numerous top quality conferences and journals in wireless networking and simulation. 